\title{
Knowledge, attitude and practice of breast self examination and breast cancer among female medical students in Taif, Saudi Arabia
}

\author{
Dalal M. Nemenqani ${ }^{1}$, Sahar H. Abdelmaqsoud ${ }^{1,2^{*}}$, Al-Hanouf A. Al-Malki ${ }^{1}$, \\ Abrar A. Oraija ${ }^{1}$, Eiman M. Al-Otaibi ${ }^{1}$ \\ ${ }^{1}$ College of Medicine, Taif University, Taif, KSA; ${ }^{*}$ Corresponding Author: abdelmaqsoudsahar@yahoo.com \\ ${ }^{2}$ Preventive Affairs Department, Alexandria University Students' Clinic and Hospital, Alexandria, Egypt
}

Received 24 December 2013; revised 26 January 2014; accepted 10 February 2014

Copyright (C) 2014 Dalal M. Nemenqani et al. This is an open access article distributed under the Creative Com- mons Attribution License, which permits unrestricted use, distribution, and reproduction in any medium, provided the original work is properly cited. In accordance of the Creative Commons Attribution License all Copyrights (c) 2014 are reserved for SCIRP and the owner of the intellectual property Dalal M. Nemenqani et al. All Copyright (C) 2014 are guarded by law and by SCIRP as a guardian.

\section{ABSTRACT}

Introduction and Research Problem: Breast cancer is the most common of all female cancers in Kingdom of Saudi Arabia. Different studies conducted in the Kingdom have shown that knowledge of females regarding breast cancer is poor. Aim of the study was to determine knowledge, attitude and practice among students of Saudi female medical university towards Breast Self Examination (BSE) and also to explore their knowledge about breast cancer. Research Methodology: An observational cross-sectional study was conducted at Faculty of Medicine, Taif University during October 2013. Sample size was 378 with mean age of $19.9 \pm 1.5$. A self administrated questionnaire was used to obtain data about knowledge, attitude and practice towards BSE and knowledge about breast cancer. Data were collected and fed to SPSS version 16 . Shape of distribution for numerical data was tested by using one sample Kolmogorov-Smirnov test. Chi-Square Test \& Fissure Exact Test (FET) were used for testing relation between categorical variables while correlation analysis was used to test the strength of relation between numeric variables. Main Results: The study revealed that only $8.2 \%$ of participants had good overall knowledge about breast cancer and BSE. Although $66 \%$ of the study sample had positive attitude towards BSE, only $17 \%$ reported that they practiced BSE monthly. A significant positive moderate correlation was found between overall knowledge score and attitude towards BSE $(r=0.449$
$\& p=0.000$ ). The same was for the frequency of BSE practice but it was found to be in a weak magnitude $(r=0.223 \& p=0.000)$. Conclusion and Recommendations: Although there was lack of knowledge about breast cancer and BSE yet, positive attitude towards BSE was encouraging. Most female medical students in our sample did not perform BSE or perform it irregularly. Therefore, more intensified awareness programs among students of medical university are necessary to keep in view their current status of breast cancer and BSE knowledge. Further researches are needed to identify causes of inadequate knowledge and practice of BSE among medical students in Taif.

\section{KEYWORDS}

Breast Self Examination; Breast Cancer; Medical Students; Saudi Arabia

\section{INTRODUCTION}

Breast cancer is the most common cancer causing the largest burden of cancer deaths in women worldwide. It is a global health problem of both developing and developed countries [1]. More than one million women are estimated to be diagnosed with breast cancer every year [2]. According to Saudi Cancer Registry (SCR) 2004, breast cancer ranked first among females in Saudi Arabia as it represented $22.4 \%$ of all newly diagnosed female cancers [3]. There are numerous risk factors associated with breast cancer. Being a woman is the main risk factor that increases probability of developing breast cancer. 
Incidence of breast cancer and its death rates generally increase with age [4]. Women with family history of breast cancer in a first degree relative are at increased risk and those with a history of breast cancer are at increased risk for developing a second breast cancer [5]. Women who started menstruation early or went through menopause late have a slightly higher risk of breast cancer [6,7]. It was found that obesity increases the risk of postmenopausal breast cancer [8]. Recent use of Hormonal Replacement Therapy (HRT) with combined estrogen and progesterone increases the risk of developing breast cancer with higher risk associated with longer use $[9,10]$. Breast cancer typically produces no symptoms when the tumor is small, later on when it has grown, it could be represented by one or more of the following symptoms and signs: painless lump in the breast, lump under the armpit, breast pain, swelling or thickness of the breast's skin, spontaneous discharge of the nipple particularly if bloody and erosion or inversion in the nipple [4]. The American Cancer Society guidelines for early detection of breast cancer recommend yearly mammogram starting at the age of forty, clinical breast examination (CBE) about every three years for women in their twenties and thirties, and every year for women at age forty and over and also recommends Breast Self Examination (BSE) for women starting their twenties [11-13]. BSE is a simple, cost free, non-invasive adjuvant screening method for the detection of early breast cancer. Its purpose is to make women familiar with both the appearance and feel of their breasts as early as possible. However, it appears that many women either perform it incorrectly or not at all [14]. Current awareness, attitude and practice about BSE and cancer breast among students of female medical university in Taif are not known. In addition, different studies conducted in Kingdom of Saudi Arabia (KSA) revealed poor knowledge of females regarding breast cancer and BSE [15-17]. Aim of this study was to determine knowledge, attitude and practice among students of female medical university in Taif towards Breast Self Examination (BSE) and also to explore their knowledge about breast cancer focusing on risk factors and clinical presentation.

\section{METHODS AND MATERIALS}

Study Design: An observational cross sectional design was conducted during October 2013. Study Setting: The study was carried out in the female section of faculty of medicine in Taif University, KSA. Study Population: All students in preparatory, second, third, fourth and fifth grades in the faculty who were available during time of the study were invited to participate in the study so that total number of participants were found to be 378 students. There were no students in the sixth grade in faculty of medicine as the oldest grade is the fifth. All partic- ipants were informed that their participation in the study is voluntary. An informed verbal response was taken before conduction of the study. No names attached to the questionnaire. Tools of Data Collection: A specifically designed self administrated closed ended questionnaire was developed by researchers after extensive literature review. The questionnaire consisted of seven sections namely; socio-demographic characteristics; family history of breast cancer and current history of abnormal breast symptoms, section to assess knowledge about BSE, another section that addresses attitude of participants towards BSE which were in the form of statements (beliefs) and a section that assesses BSE practice so students were asked if BSE is performed or not and asked to report causes of the poor performance if present, knowledge of the study sample about the warning clinical presentation of breast cancer and finally a specific section covers knowledge of breast cancer risk factors and its screening methods and one question asking about main sources of information about breast cancer. A pilot study was carried out upon twenty female students belonged to faculty of Applied Medical Sciences to detect difficulties that may arise during the study and to estimate the required time to fill the questionnaire. All pilot students said that they easily understood the questionnaire and answered it except for some words that were ambiguous that were clarified in the revised version.

Categorical responses (Yes/No/Don't know) were applied for the knowledge items. The following scoring method was used: one mark for correct answer, and zero for don't know or incorrect answers. Regarding the section of knowledge which assesses the warning clinical presentation of breast cancer it was calculated using non lump warning symptoms only [18]. The level of overall knowledge was calculated by summing scores of all knowledge questions (34 questions) yielding a total score ranging from zero to 34 and was divided into three categories as follows: Good level of knowledge $\geq 75 \%$ out of the maximum, fair level of knowledge $50 \%-<75 \%$ out of the maximum and poor level of knowledge $<50 \%$ out of the maximum.

For attitude items, 5 Likerts' scale (strongly agree/ agree/neutral/not agree/strongly not agree) was used. For a positive attitude item, scores of five, four, three, two and one for "strongly agree", "agree”, "neutral", "disagree" and "strongly disagree", respectively. This scoring was reversed for the negative attitude item. Higher scores were given to positive attitude towards BSE. Thus for the eleven attitude statements, the total score ranging from 11 to 55 and was divided into 3 categories as follows: Negative attitude 11 to 22 points, neutral attitude 23 to 43 points and positive attitude 44 to 55 points.

Data Processing and Analysis: Data were collected and fed to Statistical Package of Social Sciences (SPSS) 
version 16 at the survey was checked and entered into a database on a personal computer. The graphs were constructed using Microsoft excel software. All statistical analysis was done using 2 tailed tests and alpha error of 0.05 and $\mathrm{p}$ value less than or equal 0.05 was considered to be statistically significant. The following statistical analysis was done; descriptive statistics including mean and SD which was used to describe numerical data while percent used for categorical data. Shape of distribution for numerical data was tested using one sample Kolmogorov-Smirnov test. Chi-Square Test \& Fissure Exact Test (FET) was used for testing relation between categorical variable. Correlation analysis was used to test the strength of relation between numeric variables. Weak correlation is seen when the Pearsons' correlation coefficient $r(0.1-0.24)$ while moderate correlation is when $r$ $(0.25-0.74)$. Strong correlation will be detected when $r$ (0.75 - 0.99).

\section{RESULTS}

Three hundred seventy eight medical students were included in the study. Ages of the participants ranged from $17-24$ years with a mean of $19.9 \pm 1.5$ years. Majority $(98.7 \%)$ of students live in Taif city and single (96.6\%). About $36.5 \%$ of the respondents belonged to medical preparatory year in Taif University and only $18.8 \%$ of them reported positive family history of Breast Cancer (Table 1).

Regarding source of information about breast cancer, the most common two sources as reported by students were; media (TV/Radio) and health education lectures (46.3\% and $42.2 \%$ respectively) (Figure 1 ).

\section{Knowledge on BSE:}

The majority (89.2\%) of the participants knew that BSE is recommended to be done monthly and $84 \%$ of them know that axilla should be examined when doing BSE. However less than half of the study sample (46.8\%) was aware about the correct time of BSE (Table 2).

\section{Knowledge on breast cancer:}

Regarding knowledge about risk factors of breast cancer, the majority of the participants knew that positive family history of breast cancer and advanced age increases the risk (83.6\% and $72.5 \%$ respectively). Results revealed that more than third of the sample knew that early menarche, late menopause and eating food rich in fat are risk factors for breast cancer (all are nearly represented by $38 \%$ ). Only $28.6 \%$ of the participants in the current study answered no for the knowledge statement that mammogram is recommended to start at the age of twenty however most of them knows that CBE and mammogram are methods of early detection of breast cancer (76.2\% and 66.7\% respectively) (Table 2).

Our results showed that the most known sign of breast cancer among medical students in the current study was
Table 1. Distribution of the study sample by Socio-demographic characteristics and family history of breast cancer; breast cancer survey, Taif, 2013.

\begin{tabular}{|c|c|c|}
\hline Socio-demographic variable & $\mathbf{N}$ & $\%$ \\
\hline \multicolumn{3}{|l|}{ Age (Years) } \\
\hline $17-$ & 179 & 47.4 \\
\hline $20-24$ & 199 & 52.6 \\
\hline Mean \pm SD & \multicolumn{2}{|c|}{$19.9 \pm 1.5$} \\
\hline Total & 378 & 100 \\
\hline \multicolumn{3}{|l|}{$\underline{\text { Residence }}$} \\
\hline Taif & 373 & 98.7 \\
\hline Jeddah & 4 & 1.1 \\
\hline Makkah & 1 & 0.2 \\
\hline Total & 378 & 100 \\
\hline \multicolumn{3}{|l|}{$\underline{\text { Marital Status }}$} \\
\hline Single & 365 & 96.6 \\
\hline Married & 13 & 3.4 \\
\hline Total & 378 & 100 \\
\hline \multicolumn{3}{|l|}{ Year of University } \\
\hline Early grades (Preparatory, second) & 221 & 58.5 \\
\hline Late grades (third, fourth, fifth) & 157 & 41.5 \\
\hline Total & 378 & 100 \\
\hline \multicolumn{3}{|l|}{ Family history of Breast Cancer } \\
\hline No & 307 & 81.2 \\
\hline Yes & 71 & 18.8 \\
\hline Total & 378 & 100 \\
\hline
\end{tabular}

discharge or bleeding per nipple (50\%). The next most known danger sign was presence of lump in the breast followed by changes in the shape of the breast or nipple ( $48 \%$ and $42.9 \%$ respectively). Only $29 \%$ of the participated students were aware that inverted nipple is a sign of warning for breast cancer (Figure 2).

Level of knowledge about BSE and breast cancer:

The present work revealed that $14.6 \%$ of the study sample has good level of knowledge on clinical presentation of breast cancer compared to nearly $28 \%$ for both types of knowledge concerning BSE and risk factors of breast cancer. Only $8.2 \%$ of respondents in the current study have good overall knowledge on BSE and breast cancer (Table 3).

Level of attitude towards BSE:

More than two thirds of the study sample (67\%) had positive attitude towards BSE while no negative attitude have been reported (Figure 3 ). 


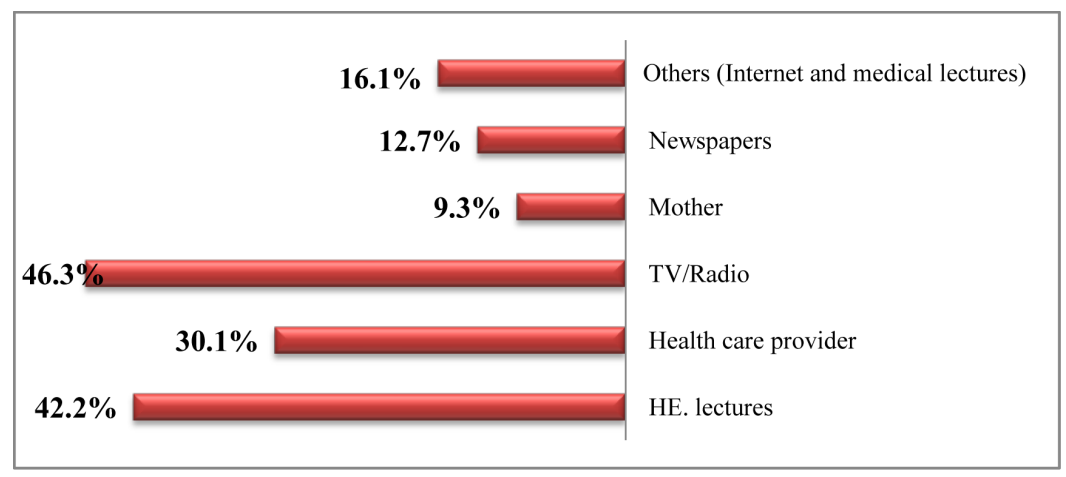

Figure 1. Distribution of participants according to sources of information about breast cancer.

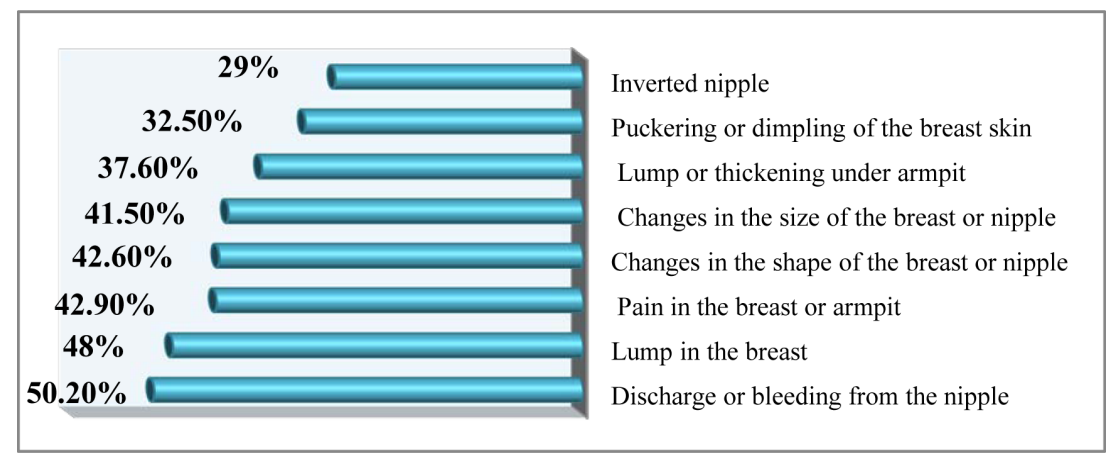

Figure 2. Distribution of the study sample according to their knowledge about clinical presentation of breast cancer.

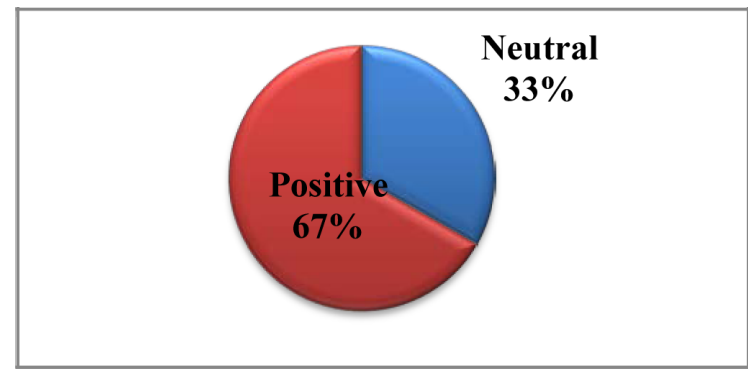

Figure 3. Distribution of the study sample according to Attitude levels towards BSE.

\section{Practice of BSE:}

The current study revealed that only $17 \%$ of female medical students reported that they perform BSE regularly once per month while 39\% of them never perform BSE (Figure 4). Among those who reported poor BSE performance, about $45.7 \%$ justified that poor practice because they do not have problems in their breasts and 20.8\% reported that they do not know how to do BSE (Figure 5).

Relationship between overall Knowledge, attitude and practice concerning BSE and some socio-demographic characteristics:

Regarding the overall knowledge about BSE and breast cancer, about 32\% of third year students' sample

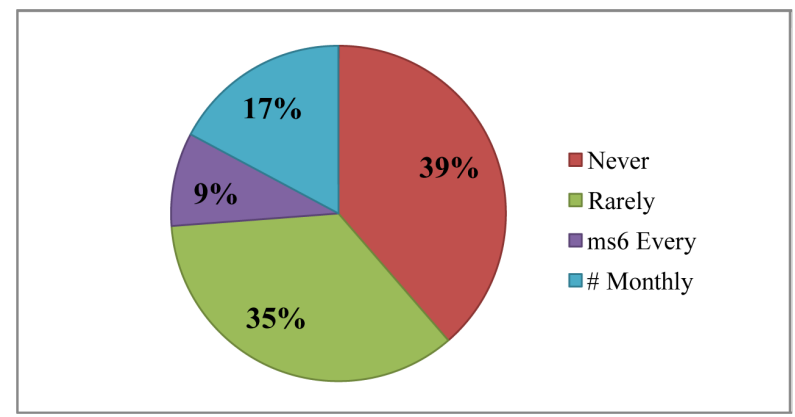

Figure 4. Distribution of the study sample according to frequency of performance of BSE.

had a good level of knowledge compared to $12.8 \%$ of the fifth year students' sample compared to $6 \%$ of the second year students' sample, $1.6 \%$ of the fourth year students' sample compared to $1.4 \%$ of the participating students from preparatory grade in the faculty. The difference was found to be highly statistically significant between the overall knowledge about BSE and breast cancer and years of university. $\left(\chi^{2}=58.7, \mathrm{p}=0.000\right)$ Concerning attitude towards BSE, the majority of students' sample belonging to fifth, third and fourth grades (89.7\%, 85.7\% and $74.2 \%$ respectively) had positive attitude compared to $55.8 \%$ of the preparatory students' sample and 55.4\% of participants in the second year of the faculty of medi- 


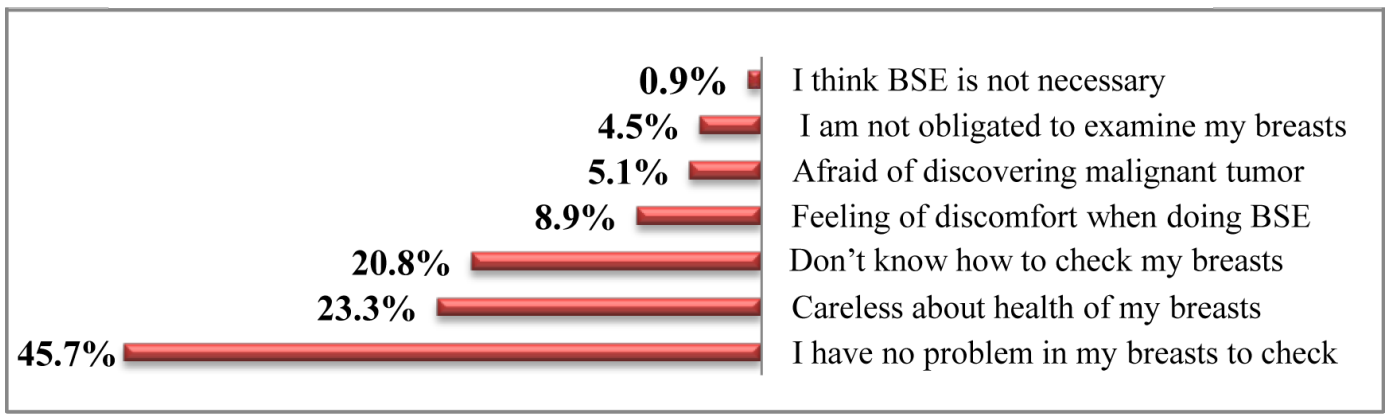

Figure 5. Reported causes of participants who mentioned that thay never perform BSE or perform it irregularly.

Table 2. Percentage of respondents having correct knowledge about BSE and breast cancer, breast cancer survey, Taif, 2013.

\begin{tabular}{|c|c|c|}
\hline Knowledge about BSE and Breast Cancer & $\mathrm{N}$ & $\%$ \\
\hline \multicolumn{3}{|l|}{ Knowledge about BSE } \\
\hline BSE is recommended to be done monthly & 337 & 89.2 \\
\hline $\begin{array}{c}\text { Suitable time to do BSE is } 7^{\text {th }} \text { day after the start of } \\
\text { menstruation }\end{array}$ & 177 & 46 \\
\hline BSE is done in front of the mirror only ${ }^{\#}$ & 211 & 55.8 \\
\hline Axilla should be examined while doing BSE & 318 & 84.0 \\
\hline Breast lump is an early warning sign for breast cancer & 57 & 15.0 \\
\hline Palm of the hands should be used while doing BSE & 278 & 73. \\
\hline BSE could be done in the supine posit & 220 & 5 \\
\hline
\end{tabular}

Knowledge about some Risk Factors of Breast Cancer

Positive Family history of Breast cancer increases the risk 31683.6

$\begin{array}{lll}\text { Advanced age increases the risk } & 274 & 72.5 \\ \text { Early menarche increases the risk } & 144 & 38.1 \\ \text { Late menopause increases the risk } & 144 & 38.1 \\ \text { Non lactating female is more prone } & 238 & 63.0 \\ & 145 & 38.4 \\ \text { ating food rich in fats increases the risk } & 200 & 52.9 \\ \text { HRT for a long duration increases the risk } & 160 & 42.3 \\ & 207 & 54.8 \\ \text { king (Active and passive) increases the risk } & 259 & 68.5 \\ & 148 & 39.2\end{array}$

Knowledge about Screening Methods of Breast Cancer

Mammogram is a method of early detection $\quad 25266.7$

CBE is a method of early detection $\quad 288 \quad 76.2$

Mammogram could discover a lump earlier than CBE 19952.6

Mammogram recommended to start at the age of twenty ${ }^{\#} \quad 108 \quad 28.6$

"reversed knowledge question (the correct answer is no).
Table 3. Frequency distribution of the study sample according to knowledge level about BSE and breast cancer, breast cancer survey, Taif, 2013.

\begin{tabular}{ccc}
\hline Knowledge about Breast Cancer and BSE & N & $\%$ \\
\hline Knowledge about BSE & 106 & 28.1 \\
Good & 152 & 40.2 \\
Fair & 120 & 31.7 \\
Poor & 378 & 100
\end{tabular}

Knowledge about Clinical Presentation of Breast Cancer

$\begin{array}{lrl}\text { Good } & 55 & 14.6 \\ \text { Fair } & 62 & 16.4 \\ \text { Poor } & 261 & 69.0 \\ \text { Total } & 378 & 100\end{array}$

Knowledge about Risk factors of Breast Cancer

$\begin{array}{lll}\text { Good } & 108 & 28.6 \\ \text { Fair } & 130 & 34.4 \\ \text { Poor } & 140 & 37.0 \\ \text { Total } & 378 & 100\end{array}$

Overall knowledge

\begin{tabular}{lcc} 
Good & 31 & 8.2 \\
Fair & 186 & 49.2 \\
Poor & 161 & 42.6 \\
Total & 378 & 100 \\
\hline
\end{tabular}

cine. A highly statistical significant difference was found between attitude towards BSE and years of university. $\left(\chi^{2}=32.1, \mathrm{p}=0.000\right)$.

About 28.2\% of the fifth year students' sample reported monthly regular performance of BSE compared to $25.8 \%$ of the fourth year students' sample compared to $21.4 \%$ of the third grade students' participants, $16.9 \%$ of 
participants from the second grade and compared to $8.7 \%$ of the participated students from the preparatory grade. The difference was found to be highly statistically significant between practice of BSE and years of university. $\left(\chi^{2}=14.3, \mathrm{p}=0.007\right)$ (Table 4).

Correlation between knowledge about breast cancer and BSE and attitude and practice of BSE:

There was a significant moderate positive correlation between total knowledge score and attitude towards BSE $(r=0.449 \& p=0.000)$. The same was for the frequency of BSE practice but it was found to be in a weak magnitude, $(r=0.223 \& p=0.000)$. There was a strong positive correlation between knowledge about risk factors of breast cancer and the overall knowledge $(r=0.853 \& \mathrm{p}=$ 0.000) (Table 5).

\section{DISCUSSION}

Breast cancer is the most common cancer in women worldwide that is why women's awareness of breast cancer is crucial. The need to evaluate breast cancer awareness/attitudes and practice of BSE among female students who are going to be the future health personnel is necessary and recommended [19]. The present study was conducted to determine knowledge, attitude and practice among Saudi female medical university students towards BSE and also to explore their knowledge about breast cancer focusing on risk factors and clinical presentation.

The result of the current study revealed that our participants had limited knowledge about breast cancer and BSE. Approximately only $8 \%$ of the respondents had good overall knowledge. The most widely known risk factors among participants were; family history (83.6\%) and advanced age (72.5\%). However knowledge about other risk factors of breast cancer was inadequate as only $42.3 \%$ of the study sample knew that lack of physical exercise increases the risk of breast cancer while a small percent of respondents recognize that early menarche,

Table 4. Distribution of the study sample according to overall knowledge, attitude level towards BSE and practice of BSE according to years of university breast cancer survey, Taif, 2013.

\begin{tabular}{|c|c|c|c|c|c|c|c|c|c|c|c|}
\hline \multirow{2}{*}{ Variable } & \multicolumn{2}{|c|}{ Preparatory } & \multicolumn{2}{|c|}{ Second } & \multicolumn{2}{|c|}{ Third } & \multicolumn{2}{|c|}{ Fourth } & \multicolumn{2}{|c|}{ Fifth } & \multirow{2}{*}{$\frac{\chi^{2}}{\mathrm{p}}$} \\
\hline & $\mathrm{N}$ & $\%$ & $\mathrm{~N}$ & $\%$ & $\mathrm{~N}$ & $\%$ & $\mathrm{~N}$ & $\%$ & $\mathrm{~N}$ & $\%$ & \\
\hline \multicolumn{12}{|l|}{ Overall Knowledge } \\
\hline Good & 2 & 1.4 & 5 & 6.0 & 18 & 32.1 & 1 & 1.6 & 5 & 12.8 & $\chi^{2}=58.7$ \\
\hline Fair & 50 & 36.3 & 33 & 39.8 & 36 & 64.3 & 40 & 64.5 & 27 & 69.3 & $p=0.000^{*}$ \\
\hline Poor & 86 & 62.3 & 45 & 54.2 & 2 & 3.6 & 21 & 33.9 & 7 & 17.9 & \\
\hline Total & 138 & 100.0 & 83 & 100.0 & 56 & 100.0 & 62 & 100.0 & 39 & 100.0 & \\
\hline \multicolumn{12}{|l|}{ Attitude towards BSE } \\
\hline Positive & 77 & 55.8 & 46 & 55.4 & 48 & 85.7 & 46 & 74.2 & 35 & 89.7 & $\chi^{2}=32.1$ \\
\hline Neutral & 61 & 44.2 & 37 & 44.6 & 8 & 14.3 & 16 & 25.8 & 4 & 10.3 & $\mathrm{p}=0.000^{*}$ \\
\hline Total & 138 & 100.0 & 83 & 100.0 & 56 & 100.0 & 62 & 100.0 & 39 & 100.0 & \\
\hline \multicolumn{12}{|l|}{ Perform BSE Once } \\
\hline per month & 12 & 8.7 & 14 & 19.6 & 12 & 21.4 & 16 & 25.8 & 11 & 28.2 & $\chi^{2}=14.3$ \\
\hline Irregular or never & 126 & 91.3 & 69 & 83.1 & 44 & 78.6 & 46 & 74.2 & 28 & 71.8 & $p=0.007^{*}$ \\
\hline Total & 138 & 100.0 & 83 & 100.0 & 56 & 100.0 & 62 & 100.0 & 39 & 100.0 & \\
\hline
\end{tabular}

*Significant p at $\leq 0.05$ levels.

Table 5. Correlation between knowledge, attitude and practice of breast cancer and BSE.

\begin{tabular}{|c|c|c|c|c|}
\hline & Correlation coefficient & Overall knowledge & Attitude towards BSE & Practice of BSE \\
\hline \multirow{2}{*}{ Overall knowledge } & r & 1 & 0.223 & 0.449 \\
\hline & $\mathrm{p}$ & - & $0.000^{*}$ & $0.000^{*}$ \\
\hline \multirow{2}{*}{$\begin{array}{c}\text { Knowledge about risk factors of } \\
\text { Breast Cancer }\end{array}$} & r & 0.853 & 0.281 & 0.457 \\
\hline & $\mathrm{p}$ & $0.000^{*}$ & $0.000^{*}$ & $0.000^{*}$ \\
\hline
\end{tabular}

$\mathrm{r}$ is the Pearson correlation coefficient ${ }^{*}$ Significant $\mathrm{p}$ at $\leq 0.05$ levels. 
late menopause and eating food rich in fat (each was represented by 38\%). Similarly; Mohamed HA et al. (2013) [20] indicated that more than two third of students agreed that family history, increasing age and history of breast cancer are the most risk factor for developing breast cancer in a study that was conducted among female medical students with mean age of 21 years in the faculty of Applied Medical Sciences at Umm Al-Qura University. On the other hand; a lower knowledge scores were reported in another study of breast cancer awareness that was conducted in Jeddah among 200 Saudi females in Jeddah [21]. She revealed that $57.5 \%$ of women were aware that family history is an established risk factor for breast cancer while only few females knew that late menopause (18.5\%), early menarche (17\%) and lack of physical exercise $(15.5 \%)$ are risk factors for breast cancer [21]. Compared to the present work, this lower knowledge score could be attributed to the difference between the two studies in the target population of each study as it is expected that medical students have higher level of knowledge than general female population.

In this study, nipple discharge or bleeding was the most frequent (50\%) identified symptom of breast cancer among participants followed by presence of lump in the breast (48\%) then change in the shape of the breast or nipple (42.9\%). Inverted nipple was known as a warning sign of this disease by only $29 \%$ of the students. In agreement to our study results, Radi SM (2013) [21] reported that breast lump (50.5\%) and bleeding or discharge per nipple (47\%) were the most common frequently identified symptoms in her study. This was consistent also with another study that was conducted among 247 university students in Al-Madina Al Muonawara region which reported that students were aware of painless lump in the breast or axilla (59.5\%), bloody or any discharge from the nipple (42.9\%) and inverted nipple (27.9\%) [22].

Although $89 \%$ of participants in the present survey correctly identified that BSE is recommended to be done monthly and on a regular basis; yet less than half of the study sample (46.8\%) was aware about the correct time of BSE. Al Junaibi et al. (2011) [23] who studied knowledge and awareness of breast cancer among university female students in Muscat Sultanate of Oman reported another findings as $72.6 \%$ knew that BSE should be performed monthly while about $61 \%$ of respondents could identify the correct timing for BSE performance. Habib et al. (2010) [22] in their study found that about $65.9 \%$ of university students correctly answered to the question of the appropriate time to perform BSE.

The main sources of information regarding breast cancer reported by participants in the current study were; media (Television/Radio) (46.3\%) followed by health education lectures (42.2\%). Another study revealed that newspaper and peer groups were the most common sources of student information about breast cancer [20]. Near findings were reported by Habib et al. (2010) [22] as $56 \%$ of university students in their study identified Television/Radio as the main sources of information about breast cancer while 34.3\% mentioned that newspaper is their source. Media played a significant role as the main source of information about breast cancer; therefore an important effort should be intensified in using these media to create breast cancer awareness within the Saudi community. This will emphasize the message of early detection which will reach large number of people in the community.

Most respondents in the current work had poor to fair overall knowledge score. This could be attributed to the fact that $73 \%$ of the total sample size in the current study were junior medical students (preparatory, second and third grades) who did not receive yet in-depth breast cancer curriculum. The other factor was that we chose a specific scoring system to measure knowledge of clinical presentation of breast cancer based on non lump symptoms [18].

More than two third (67\%) of participants had positive attitude towards BSE. No negative attitude has been reported in the present work. This is considered a good environment to correct knowledge and to improve practice. The positive attitude in this survey could be explained by the type of study of our respondents which made them more involved and interested in health problems within their community. Active voluntary participation of female medical students in Taif University in the regular annual breast cancer awareness campaign is another factor. Previous findings "positive attitude towards BSE" was consistent with other studies that address attitude towards breast cancer in Malaysia and India [24,25].

The present survey revealed that only $17 \%$ of the respondents reported that they perform BSE monthly while $39 \%$ never perform it. Some causes reported by students who had poor BSE practice were; absence of symptoms in the breast (45.7\%), carelessness (23.3\%) and lack of knowledge about steps of BSE (20.8\%). Another study conducted at king Abdulaziz University in Jeddah revealed that $33 \%$ of Saudi nursing students at perform BSE monthly [26]. On the other hand, about $66 \%$ of the nursing students reported regular performance of BSE in a study conducted in Riyadh [27]. About $40 \%$ of participated subjects in Riyadh study [27] learned facts regarding BSE in their nursing curriculum in contrast to medical students in our survey; this could explain the difference between findings of the present work and that Riyadh study.

Regarding good knowledge in the present work among the study sample, the highest score of good overall 
knowledge was observed among participants of third year (32\%) and among participated students from fifth year (12.8\%). Participants from third year were actively involved in a recently conducted breast cancer awareness campaign prior to the start of this study. The highest positive attitude and the more regular practice of BSE were seen among fifth year's students $(89.7 \%$ and $28.2 \%$ respectively). A highly statistical significant difference was found between attitude towards BSE and years of university $\left(\chi^{2}=32.1, \mathrm{p}=0.000\right)$. The same finding was found also for practice $\left(\chi^{2}=14.3, \mathrm{p}=0.007\right)$. Senior medical students are more exposed to medical knowledge and this could explain the highest percentage of positive attitude and of regular practice seen among them compared to juniors. Our study revealed a positive correlation between overall knowledge and practice of BSE $(r=0.449 ; P=0.000)$ illustrating the desire among this population to acquire correct knowledge regarding breast cancer and BSE. Also, this finding brings to light that if awareness and health education programs are conducted in an intensive and planned form, it might result in positive healthy practices.

\section{CONCLUSION}

Although there was lack of knowledge about breast cancer and BSE yet, the positive attitude towards BSE was encouraging. Most female medical students in our sample did not perform BSE or perform it irregularly. This might be an obstacle to screening program and early diagnosis of breast cancer. Therefore, more intensified awareness programs among medical university students are necessary to keep in view their current status of breast cancer and BSE knowledge. Also, further researches are needed to identify causes of inadequate knowledge and practice of BSE among students in Taif University. More utilization of Media as an important source of breast cancer is important to improve awareness among the community.

\section{ACKNOWLEDGEMENTS}

Many thanks to Dr Shehta Farag; Assistant Lecturer of Biostatistics; High Institute of Public Health; Alexandria University; Egypt for his valuable advises concerning data analysis phase.

\section{REFERENCES}

[1] WHO (2013) Breast cancer: Prevention and control. WHO 2012. http://www.who.int/cancer/detection/breastcancer/en/

[2] Coughlin, S.S. and Ekwueme, D.U. (2009) Breast cancer as a global health concern. Cancer Epidemiology, 33, 315-318. http://dx.doi.org/10.1016/j.canep.2009.10.003

[3] Al-Eid, H.S. and Arteh, S.O. (2004) Ministry of health.
Saudi cancer registry. Cancer Incidence Report, Saudi Arabia.

[4] American Cancer Society (2013) Breast cancer facts and figures 2013-2014.

http://www.cancer.org/acs/groups/content/@research/doc uments/document/acspc-040951.pdf

[5] Collaborative Group on Hormonal Factors in Breast Cancer (2001) Familial breast cancer: collaborative reanalysis of individual data from 52 epidemiological studies including 58,209 women with breast cancer and 101,986 women without the disease. Lancet, 358, 1389-1399. http://dx.doi.org/10.1016/S0140-6736(01)06524-2

[6] Kelsy, J.L., Gammon, M.D. and Jhon, E.M. (1993) Reproductive factors and breast cancer. Epidemiologic Reviews, 15, 36-47.

[7] Collaborative Group on Hormonal Factors in Breast Cancer (2012) Menarche, menopause and breast cancer risk: Individual participant meta-analysis, including 188964 women with breast cancer from 117 epidemiological studies. The Lancet Oncology, 12, 11419-11451.

[8] World Cancer Research Fund (2007) American Institute of Cancer Research. Food, nutrition, physical activity and the prevention of cancer: A global perspective. AICR, Washington DC.

[9] Rossouw, J.E., Andrson, G.L., Prentice, R.L., et al. (2002) Risks and benefit of estrogen plus progestin in healthy postmenopausal women: Principal results from Women's Health Initiative randomized controlled trial. JAMA, 288, 321-333. http://dx.doi.org/10.1001/jama.288.3.321

[10] Chleboski, R.T., Andrson, G.L., Gass, M., et al. (2010) Estrogen plus progestin and breast cancer incidence and mortality in postmenopausal women. JAMA, 304, 16841692. http://dx.doi.org/10.1001/jama.2010.1500

[11] Kerlikowske, K., Hubbard, R.A., Miglioretti, D.L., et al. (2011) Comparative effectiveness of digital versus filmscreen mammography in community practice in the United States: A cohort study. Ann Intern Med, 155, 493-502. http://dx.doi.org/10.7326/0003-4819-155-8-201110180-0 $\underline{0005}$

[12] Smith, R.A., Saslow, D., Sawyer, K.A., et al. (2003) American Cancer Society Guidelines for breast cancer screening: Update 2003. CA: A Cancer Journal for Clinicians, 53, 141-169.

[13] Semiglazov, V.F., Moiseenko, V.M., Manikhas, A.G., et al. (1999) Intrim results of a prospective randomized study of self-examination for early detection of breast cancer. Voprosy Onkologii, 45, 265-271.

[14] American Cancer Society (2002) Cancer statistics. CA: A Cancer Journal for Clinicians, 52, 10-11.

[15] Milaat, W.A. (2000) Knowledge of secondary school female students on breast cancer and breast self examination in Jeddah, Saudi Arabia. Eastern Mediterranean Health Journal, 6, 338-344.

[16] Maha, S.A. and Hadi, A. (2000) Breast cancer awareness among health professionals. Annals of Saudi Medicine, 20, 135-136.

[17] Kashgari, R.H. and Ibrahim, A.M. (1996) Breast cancer: 
Attitude, knowledge and practice of breast self examination of 157 Saudi women. Journal of Family and Community Medicine, 3, 10-13.

[18] Linsell, L., Forbes, L.J.L., Burgess, C., Kapari, M., Thurnham, A. and Ramirez, A. (2010) Validation of a measurement tool to assess breast cancer. European Journal of Cancer, 46, 1374-1381.

http://dx.doi.org/10.1016/j.ejca.2010.02.034

[19] Çavdar, Ý., Akyolcu, N., Özbaş, A., Öztekin, D., Ayoğlu, T. and Akyüz, N. (2007) Determining female physicians' and nurses' practices and attitudes towards breast selfexamination in Istanbul, Turkey. Oncology Nursing Forum, 36, 1218-1221.

http://dx.doi.org/10.1188/07.ONF.1218-1221

[20] Mohamed, H.A., El-Naggar, N.S. and Sayed, H.Y. (2013) Knowledge, attitudes and practices regarding breast self examination among female undergraduate students in the faculty of applied medical sciences at Umm Al-Qura University. Journal of American science, 9, 622-632.

[21] Radi, S.M. (2013) Breast cancer awareness among Saudi females in Jeddah. Asian Pacific Journal of Cancer Prevention, 14, 4307-4312.

http://dx.doi.org/10.7314/APJCP.2013.14.7.4307
[22] Habib, F., Salman, S., Safwat, M. and Shalaby, S. (2010) Awareness and knowledge of breast cancer among university students in Al Madina Al Munawara reigon. MEJC, 1, 159-166.

[23] Al Junaibi, R.M. and Khan, S.A. (2011) Knowledge and awareness of breast cancer among university female students in Muscat, Sultanate of Oman-A pilot study. Journal of Applied Pharmaceutical Science, 1, 146-149.

[24] Rosmawati, N.H.N. (2010) Knowledge, attitude and practice of breast self examination among women in a SubSaharan area in Terengganu, Malaysia. Asian Pacific Journal of Cancer Prevention, 11, 1503-1508.

[25] Doshi, D., Reddy, B.S., Kulkarni, S. and Karunakar, P. (2012) Breast self examination: Knowledge, attitude and practice among female dental students in Hyderabad city, India. Indian Journal Palliate Care, 18, 68-73. http://dx.doi.org/10.4103/0973-1075.97476

[26] Yousuf, Sh.A. (2010) Breast cancer awareness among Saudi nursing students. Medicine Science, 17, 67-78.

[27] Alsaif, A.A. (2004) Breast self examination among Saudi female nursing students in Saudi Arabia. Saudi Medical Journal, 25, 1574-1578. 